\title{
Readaptação Funcional do Estomizado: Relato de Experiências Vividas
}

\author{
Functional Readaptation of Stomized Patients: Report of Experiences
}

\author{
Readaptación Funcional del Ostomizado: Relato de Experiencias Vividas
}

Jane Walkiria da Silva Nogueira1, Ivone Kamada', Glauce Araújo Ideião Lins

\begin{abstract}
RESUMO
O retorno ao trabalho é essencial para a inclusão social de estomizados. Desse modo, objetivou-se analisar os aspectos envolvidos na reinserção ocupacional destes sujeitos e a participação do enfermeiro nesse processo. Tratou-se de um estudo descritivo e exploratório, de abordagem qualitativa, que foi realizado por meio de entrevista semiestruturada, com dez indivíduos adultos com estomia intestinal definitiva há mais de um ano, na condição de trabalhador ativo ou inativo. Utilizou-se análise temática de conteúdo. Os resultados revelaram que, para estes indivíduos, o trabalho é percebido como uma estratégia para enfrentar a nova condição de vida. Segundo os participantes, os fatores que mais dificultam o seu retorno ao ambiente de trabalho são o uso da bolsa coletora, a falta de banheiro adaptado e o desconhecimento da sociedade sobre o que é uma pessoa estomizada. Dentre os fatores que facilitam, destacaram-se a possibilidade de realizar o sistema de irrigação, a flexibilidade de horário, ter um negócio próprio e o apoio de empregadores e colegas de trabalho. Conclui-se que ainda há lacunas em relação à participação do enfermeiro no processo de retorno ao trabalho das pessoas com estoma. Nenhum participante referiu ter recebido informações deste profissional quanto à possibilidade de retorno às suas atividades laborais. Ademais, esta investigação permitiu identificar não só os desafios que os estomizados enfrentam ou podem enfrentar quando optam pelo retorno às suas atividades de trabalho, como também a necessidade de intensificar as ações educativas junto à sociedade em geral, sobre o que é uma pessoa com estoma intestinal.
\end{abstract}

DESCRITORES: Estomaterapia. Saúde do trabalhador. Estomas cirúrgicos. Enfermagem do trabalho.

\begin{abstract}
Returning to work is essential for the social inclusion of stomized people. Thus, the aim of this study was to analyze the aspects involved in the professional reinsertion of these individuals and the participation of nurses in such process. A descriptive, exploratory and qualitative study was developed by means of semi-structured interviews with ten adults who had undergone definitive intestinal ostomy over a year before the study, and who were active or inactive workers. It was used a thematic content analysis. Results revealed that, for these people, work is seen as a strategy to face their new life condition. According to the participants, the factors that most hampered their return to work was the use of an ostomy bag, the lack of adapted restrooms, and society's lack of knowledge regarding what an stomized person is. Among the factors that facilitated their return, they highlighted the possibility of performing the irrigation system, time flexibility, having their own business, and support from employers and workmates. In conclusion, there are still gaps with regard to the participation of nurses in the process of stomized people returning to work. None of the participants mentioned having received information from nurses as to the possibility of returning to their labor activities. Moreover, this study allowed identifying not only the challenges that stomized people face or might face when they decide to return to work, but also that it is necessary to intensify educational actions with the society in general regarding what a person with intestinal ostomy is.
\end{abstract}

DESCRIPTORS: Stomatherapy. Occupational health. Surgical stomas. Occupational health nursing.

'Universidade de Brasília (UnB) - Brasília (DF), Brasil. Endereço para correspondência: SQN 311 - Bloco B - apto. 204 - Asa Norte - CEP: $70757-020$ -

Brasilia (DF), Brasil - E-mail: janewalkiria@gmail.com

Artigo recebido em: 06/09/2015 - Aceito para publicação em: 18/12/2015 


\section{RESUMEN}

El retorno al trabajo es esencial para la inclusión social de los ostomizados. De ese modo, se objetivó analizar los aspectos involucrados en la reinserción laboral de estos sujetos y la participación del enfermero en el proceso. Se trató de un estudio descriptivo, exploratorio, de abordaje cualitativo, aplicándose una entrevista semiestructurada en diez individuos adultos con estomía intestinal definitiva de antigüedad superior a un año, en condición de trabajador activo o inactivo. Se utilizó el análisis temático del contenido. Los resultados expresaron que, para estos individuos, el trabajo es visto como una estrategia para enfrentar a suya nueva condición de vida. Según los participantes, los factores que más dificultan su retorno al ámbito laboral son el uso de la bolsa colectora, la falta de baños adaptados y el desconocimiento social sobre lo qué es una persona ostomizada. Citan también entre los factores que facilitan la posibilidad de realizar el sistema de irrigación, la flexibilidad de horarios, tener un negocio propio y el apoyo de los empleadores y compañeros de trabajo. Se concluye que hay vacíos respecto a la participación del enfermero en el retorno laboral del ostomizado. Ningún participante refirió haber recibido indicaciones de estos profesionales sobre la posibilidad del retorno laboral. Además, la investigación permitió identificar los desafíos enfrentados, o que pueden enfrentar, los ostomizados cuando optan por retornar a sus actividades laborales, y que es necesario intensificar las campañas educativas para la sociedad en general sobre lo que es una persona con ostomía intestinal.

DESCRIPTORES: Estomaterapia. Salud laboral. Estomas quirúrgicos. Enfermería del trabajo.

\section{INTRODUÇÃO}

O trabalho constitui uma atividade central nas vidas social, psicológica e econômica da grande maioria das pessoas. Trabalhar faz o ser humano sentir-se útil e inserido em um grupo, sendo essencial para a construção/reconstrução da sua identidade, além de permitir o sustento financeiro do indivíduo e de sua família ${ }^{1}$. Porém, acontecimentos imprevisíveis podem limitar temporariamente a pessoa à vida laborativa, como é o caso de indivíduos que se submetem à confecção cirúrgica de um estoma intestinal ${ }^{2}$.

A confecção de um estoma intestinal pode representar para os indivíduos alterações de autoimagem, confiança, independência, dignidade e papéis construídos socialmente ${ }^{3}$. Ademais, tomados pelos sentimentos de medo, angústia e insegurança, esses indivíduos acreditam não serem capazes de retornarem às suas atividades normais de vida após o período de hospitalização $0^{4,5}$.

Neste sentido, muitos destes indivíduos afastam-se do convívio social e do trabalho por vergonha de seus colegas, clientes e empregadores, que é relacionado à falta de controle esfincteriano, à produção contínua de gases ou flatulência e ao uso de equipamentos adjuvantes no cuidado ao estoma ${ }^{6}$. Essa realidade tem levado muitos indivíduos ao abandono de suas atividades de trabalho formal e à busca pela aposentadoria precoce ${ }^{7,8}$.

A aposentadoria precoce constitui um dos direitos dos estomizados, conforme Decreto 5.296, de 2 de dezembro de 2004 , que inclui as pessoas com estomias entre aquelas com deficiência física, portanto estão sujeitas às determinações legais brasileiras pertinentes a todas as pessoas com deficiência ${ }^{9}$. Desse modo, os indivíduos com estoma estão respaldados legalmente pela Política Nacional para a Integração da Pessoa Portadora de Deficiência (podendo usufruir das cotas empregatícias) e pela Política de Saúde do Trabalhador, as quais lhes concedem o direito de retornar às suas atividades profissionais em condições adequadas à sua capacidade física e limitações ${ }^{10,11}$.

Dessa forma, o processo de cuidar ao estomizado deve ser realizado de forma integral, considerando as necessidades do indivíduo, sejam elas de ordem emocional, física ou social ${ }^{11,12}$.

Ao investigar publicações nacionais atuais sobre esta temática, verificou-se que, apesar dos esforços de estudiosos sobre este assunto ${ }^{1-3,7,8,13-16}$, ainda persiste a carência de pesquisas que abordem a readaptação do trabalhador estomizado no ambiente de trabalho, principalmente na área da Enfermagem, e as repercussões que o afastamento da atividade laboral tem na vida destes ${ }^{8,14,15}$. Logo, a permanência da lacuna de artigos científicos sobre este assunto justifica a realização desta investigação.

Diante deste contexto, objetivou-se analisar os aspectos envolvidos na reinserção ocupacional do estomizado, considerando a participação do enfermeiro nesse processo. Entende-se que o resultado desta investigação poderá contribuir para que os profissionais envolvidos, em especial, com a Saúde Ocupacional, criem ou reanalisem as estratégias utilizadas no processo de readaptação das pessoas com estomas nos âmbitos profissional e social. 


\section{MÉTODO}

Trata-se de um estudo exploratório e descritivo, com abordagem qualitativa. $\mathrm{O}$ espaço delimitado para a investigação foi o Serviço Ambulatorial de Enfermagem em Estomaterapia (SAEE) e a Associação dos Ostomizados de Brasília (AOSB) do Hospital Universitário da Universidade de Brasília (HUB da UnB), em que são realizadas reuniões mensais, nas primeiras sextas-feiras de cada mês. Em tais encontros, são abordados temas, pelos profissionais de saúde, referentes ao cotidiano da pessoa com estoma. Os participantes da pesquisa constituíram-se de indivíduos que frequentam essas reuniões mensais e/ou são atendidos no referido Serviço Ambulatorial. Foram estabelecidos como critérios de inclusão: ter idade entre 18 e 64 anos; ter estomia intestinal há mais de um ano e em caráter definitivo; ter sido trabalhador em algum momento de sua vida, independente de exercer esta atividade atualmente e não possuir complicações que os impeçam de exercer atividades laborais.

Os dados foram coletados de fevereiro a março de 2013, após aprovação pelo Comitê de Ética em Pesquisa da Faculdade de Medicina da UnB, sob o protocolo 078/2012.

O instrumento utilizado para coletar os dados foi um roteiro de entrevista semiestruturada individual, com adaptações para este estudo, proposto por Mauricio ${ }^{7}$,que tem se dedicado a estudos sobre a inclusão laboral da pessoa com estoma intestinal. Este objeto é composto de duas partes. A primeira inclui dados de caracterização do participante como sexo, idade, estado civil, escolaridade, pessoas que residem com o estomizado, renda familiar aproximada, número de pessoas que trabalham e moram na residência; atividade profissional exercida antes da estomia; tempo de estomizado; doença que levou à geração do estoma; presença de complicações relacionadas ao estoma e vínculo empregatício atual.

A segunda parte é composta por cinco questões referentes ao mundo do trabalho do estomizado, as quais abrangem os seguintes aspectos: atividade produtiva remunerada após a realização do estoma; retorno ou não do estomizado ao mundo do trabalho; facilidades e dificuldades para realizar a atividade produtiva; sugestões do entrevistado para facilitar a inclusão da pessoa estomizada no mundo do trabalho e a importância do profissional de Enfermagem nesse processo de retorno ao mundo do trabalho.

Neste estudo, as adaptações feitas no instrumento para coleta de dados de Mauricio ${ }^{7}$ referem-se à substituição do termo "doença” para a "causa" que levou à geração do estoma e a frase "entrevista sobre aspectos referentes ao mundo do trabalho" para "entrevista sobre os aspectos referentes à reinserção ocupacional do indivíduo estomizado". Além disso, foi excluído o item relacionado à renda familiar aproximada.

Para a realização das entrevistas, solicitou-se ao presidente da AOSB uma lista dos nomes e contatos dos sujeitos inscritos na associação dos estomizados. Desta forma, o convite foi feito por meio de contato telefônico e a entrevista foi agendada em locais sugeridos pelo entrevistado ou pelas pesquisadoras, tais como: onde acontecem as reuniões da AOSB e na residência ou no ambiente de trabalho dos estomizados. Em todos os locais, nos quais as entrevistas foram realizadas, houve a preocupação de selecionar áreas que não tivessem estímulos externos ou ruídos que pudessem influenciar o seu desenvolvimento. Apenas uma pessoa se recusou a participar do estudo. As entrevistas foram gravadas em um aparelho digital e duraram, em média, 30 minutos.

Após a realização de cada entrevista, conduziu-se a escuta atenta das gravações e, posteriormente, a transcrição para a leitura textual. A coleta de dados foi encerrada quando houve saturação dos dados, levando-se em consideração a repetição dos conteúdos, as falas e os significados. A análise dos dados foi realizada após a transcrição na íntegra dos relatos. Foi utilizada a análise de conteúdo, na modalidade temática proposta por Minayo ${ }^{17}$. Os dados foram organizados em grupos temáticos e, em seguida, organizados em categorias e analisados com base na literatura pertinente ao tema.

Em relação aos preceitos éticos, estes foram embasados na Resolução 466/12 do Conselho Nacional de Saúde, do Ministério da Saúde ${ }^{18}$. Também foi solicitada aos participantes a assinatura voluntária do termo de consentimento livre e esclarecido (TCLE). Para a garantia de confiabilidade e anonimato dos participantes, estes foram referenciados com a letra " $E$ ", seguidos das siglas numéricas de 1 a 10.

\section{RESULTADOS E DISCUSSÃO}

Participaram do estudo 10 adultos, sendo 4 (40\%) do sexo feminino e 6 (60\%) do masculino, cuja idade variou de 41 a 61 anos. Quanto à escolaridade, um entrevistado tinha ensino superior completo, quatro tinham superior incompleto, quatro com ensino médio incompleto e um com ensino 
médio completo. Em relação ao estado civil, sete eram casados, um era separado e dois eram solteiros. Nenhum participante residia sozinho, moravam com pelo menos um membro da família.

A presença de um(a) companheiro(a) ou outro familiar na residência pode significar apoio às pessoas estomizadas, as quais se sentirão mais seguras durante todo o processo de reabilitação, além de ser uma ajuda nas despesas do lar, auxiliando nas possíveis dificuldades financeiras que poderão surgir ${ }^{7,14}$.

No que se refere ao trabalho anterior à realização do estoma, todos os indivíduos tinham uma atividade laboral: três secretárias, três pequenos empresários, um técnico têxtil, um gerente administrativo, um porteiro e um instalador de telefone. Após a realização da estomia, identificou-se que oito eram aposentados por invalidez, um recebia auxílio-doença e um continuava exercendo a mesma atividade prévia à realização da cirurgia. Dentre os sujeitos que recebiam aposentadoria, quatro exerciam trabalho informal e dois continuavam exercendo um trabalho formal. Quanto a estes últimos indivíduos, de acordo com as leis que regulamentam a aposentadoria dos trabalhadores por invalidez, eles não poderiam retornar ao trabalho formal ${ }^{7,8,13,14}$. Entretanto, eles acabam voltando em função das necessidades financeiras pessoais e familiares, do baixo valor da aposentadoria, além do bem-estar psicológico que a atividade laboral lhes proporciona. A maioria (70\%) deles relata que trabalhar faz com que não fiquem pensando o tempo inteiro no fato de estarem com um estoma intestinal.

Esse resultado foi evidenciado por um estudo com indivíduos estomizados, o qual mostrou que, dentre os 20 sujeitos entrevistados, 15 exerciam atividade laboral e 12 recebiam concomitantemente auxílios governamentais, ou seja, estes indivíduos trabalhavam na ilegalidade e recebiam seus auxílios. A alegação era de que os benefícios se mostravam insuficientes ao seu sustento financeiro e familiar, o que os levava a buscar algum complemento para a sua renda, em empregos informais ${ }^{7,13,14}$.

Quanto à análise das entrevistas, emergiram quatro categorias: o significado do trabalho para a pessoa com estoma intestinal; fatores que dificultam a reinserção da pessoa com estoma intestinal no ambiente de trabalho; fatores que facilitam a reinserção da pessoa com estoma intestinal no ambiente de trabalho e o enfermeiro no processo de retorno da pessoa com estoma intestinal ao mundo do trabalho.

\section{O significado do trabalho para a pessoa com estoma intestinal}

Neste estudo, o trabalho é visto como uma estratégia de enfrentamento utilizada pelos estomizados para conviver melhor com a sua nova condição de vida, ou seja, ter uma colostomia definitiva.

[...] Se você tiver a oportunidade de trabalhar é melhor, porque a cabeça funciona melhor, se você ficar em casa todo o tempo pensando que tem uma ostomia e não pode fazer nada, você acaba não vivendo mais e a sua qualidade de vida piora. Aí é uma bola de neve, se eu tô [sic] ruim mentalmente, psicologicamente, meu organismo vai começar achar ruim e os problemas com certeza vêm. - E5

[...] Eu ficava nervoso de ficar em casa, brigava com a mulher, ficava pensando no meu problema, por isso eu quis voltar a trabalhar. - E8.

Outro aspecto referido pelos participantes, em relação ao trabalho, foi que a falta da atividade laborativa poderia levar ao isolamento social e à depressão.

[...] ficar parado, a gente pensa demais, é pior, tem que procurar alguma coisa para estimular você a viver melhor. Se você ficar pensando: eu tenho um estoma, a gente não consegue nem viver. Tem gente que entra em depressão porque tem muita coisa que a gente fazia e não faz mais. - E7

[...] Quando eu ficava em casa, me isolei muito. Quero dizer que a gente tem que trabalhar mesmo, ficar em casa é muito depressivo. - E2

Esses achados corroboram os resultados encontrados em outros estudos que investigaram o processo de inclusão no trabalho da pessoa estomizada. Nessas investigações, além das questões financeiras, os entrevistados referiram o trabalho como uma importante forma de distração, de ocupação da mente e de reintegração social ${ }^{8,13-15}$.

Vale ressaltar que até mesmo os indivíduos, que não estão trabalhando e recebem algum benefício do Governo, referem o desejo de voltar a trabalhar: 
[...] Eu tenho vontade de trabalhar fora de casa, mas meu marido não deixa porque eu sofri muito e ele tem cuidado comigo.-E10

Neste sentido, o trabalho é visto como elemento fundamental para a existência sem depressão de um sujeito estomizado9. A sua falta pode levar o estomizado à ociosidade, ao isolamento social e ao sentimento de inutilidade ${ }^{5,6,19}$. Portanto, fica evidente a vontade do estomizado de se sentir útil e pertencer a um grupo.

Para os participantes desta investigação, o trabalho constitui um fator determinante para o seu bem-estar psicológico, além de ser um coadjuvante para evitar a depressão e o afastamento social. Dessa forma, é possível que o retorno ao trabalho, formal ou informal, possa ser um elemento fundamental no processo de reabilitação da pessoa com estoma definitivo.

\section{Fatores que dificultam a reinserção da pessoa com estoma intestinal no ambiente de trabalho}

Conforme anteriormente, o estomizado sofre alterações em sua vida física, psicológica, social e, principalmente, na sua atividade laboral. Nessa perspectiva, muitos indivíduos relataram o uso da bolsa coletora como principal fator que dificulta a reinserção no ambiente de trabalho.

[...] Eu trabalhar de bolsa não dá, pode soltar gases, as pessoas podem escutar e eu morro de vergonha, a bolsa enche de ar, enche de fezes. Por exemplo, se eu tivesse [sic] trabalhando e a bolsa começasse a vazar, o que eu iria fazer? Dizer para o chefe, espere um pouquinho que eu tenho que me limpar? Não dá. A bolsa de colostomia é constrangedora. - E10

[...] Eu faço irrigação, se tivesse que usar bolsa, eu não voltaria a trabalhar porque incomoda, é indiscreto, parece que todo mundo está vendo, cheira mal, transpira, machuca, faz barulho. - E2

Desse modo, percebe-se que o uso da bolsa coletora é, muitas vezes, o principal motivo para impedir o indivíduo de voltar a trabalhar em função do desconforto e incômodo do equipamento, da presença de dor e gases e da perda do controle esfincteriano. Eles acreditam que não encontrarão empregadores e colegas de trabalho que compreendam essa situação, sendo evidente o medo da rejeição.
[...] A maior dificuldade do estomizado é essa: a convivência com o público. Você fica um pouco receoso, desconfiado, se de repente vai aparecer um barulho. As pessoas não vão entender, mesmo que você explique. - E1

Assim, a presença da estomia e a bolsa coletora geram autorrejeição e afastamento das outras pessoas. O indivíduo estomizado reluta em expor a sua condição frente à sociedade, preferindo se esconder; por consequência, a rejeição no trabalho e o medo do preconceito são temores constantes na vida dos estomizados ${ }^{13,14,19}$.

Outra dificuldade citada pelos entrevistados foi a falta de um banheiro adaptado. Na maioria dos lugares, o que se encontra é um banheiro para deficientes físicos, mas não específico para estomizados. Além disso, uma grande parte destes locais não tem ducha higiênica, um artefato que ajudaria o estomizado no processo de limpeza e esvaziamento do dispositivo coletor.

\section{[...] é uma realidade complicada, a maioria dos lugares não tem ainda um banheiro adaptado e, principalmente, não tem banheiro para estomizado. No meu trabalho, existe uma promessa de um banheiro adaptado para estomizado, mas ainda não foi feito nada lá. - E5}

Estudos anteriores já mostraram a necessidade destes indivíduos de terem um banheiro adaptado para poderem sentir mais segurança na hora de optarem por retornarem ao mercado de trabalho formal ${ }^{7,8,12-14}$. Iniciativas para aprimorar a qualidade de vida destes indivíduos, como a construção de banheiros adaptados e propostas de políticas públicas para a pessoa com estomia, têm sido realizadas pelas entidades representativas destes sujeitos.

No entanto, os resultados desta pesquisa revelaram que, apesar dos esforços feitos pelas sociedades representativas dos estomizados, a problemática da falta de uma estrutura física para receber os trabalhadores estomizados permanece. A falta de conscientização tanto na área institucional como na estatal a respeito dos espaços físicos para indivíduos com deficiência física, seja com ou sem estomia, ainda é um problema a ser enfrentado.

A falta de conhecimento da sociedade sobre as transformações que ocorrem com as pessoas estomizadas constitui outro fator citado pelos participantes deste estudo que contribui para dificultar a reinserção destes no ambiente de trabalho. 
[...] É necessário que a sociedade tome conhecimento disso, porque a pessoa estomizada vai mais vezes ao banheiro e de repente está com uma chefia que não entende isso, porque a pessoa se ausenta tantas vezes, vai para o banheiro e fica lá de 15 a 20 minutos. - E5

[...] É preciso mostrar para a sociedade que existem pessoas estomizadas. Pelo fato de as pessoas não saberem o que é uma estomia, um estomizado, ninguém se prepara para isso. - E5

A readaptação do trabalhador no ambiente de trabalho deve envolver a articulação de programas de reabilitação profissional, com medidas que possam incluir aspectos flexíveis, característicos do trabalho atual, tais como: mudança de função; alteração das jornadas de trabalho e produtividade por cumprimento de metas. Sabe-se que o estomizado ou qualquer outro trabalhador que tenha uma deficiência física, para retornar ao trabalho, precisa ser avaliado e liberado pela perícia médica para retornar às suas funções ou ser readaptado a outro setor de acordo com os seus limites.

Entretanto, raramente esse trabalhador sofre mudança de função, pois é visto por muitos empregadores como incapazes de trabalhar novamente em função de suas limitações, as quais podem interferir na produtividade e no lucro da empresa. Ademais, este processo de incluir-se a uma nova função pode ser extremamente desgastante, principalmente quando os indivíduos não recebem a qualificação e o acompanhamento adequados ${ }^{12-15}$.

[...] Empresa particular visa muito lucro, podia me tirar pra [sic] motorista, despachante, um setor que não precisasse de esforço físico e não quiseram fazer isso. - E8

Nesta perspectiva, é necessária a criação de novas oportunidades de emprego aos estomizados, as quais sejam adequadas às suas condições de saúde. Um indivíduo com estoma precisa adotar vários cuidados e procedimentos para manter-se ou se incluir no mundo do trabalho. Ele não pode exercer atividades nas quais permaneça em pé ou sentado durante todo o tempo e naquelas que demandam esforço físico em excesso. Deve ter acesso a um banheiro adequado para sua higienização, ter uma alimentação equilibrada e garantia de retorno às consultas médicas com periodicidade regular ${ }^{7,8,12,13}$. Logo, muitas empresas não manifestam interesse em empregar esses indivíduos, devido aos gastos que teriam com as adequações do ambiente de trabalho, que vão diretamente contra a ideologia típica capitalista ${ }^{13}$.

Portanto, o principal fator que dificulta a reinserção das pessoas estomizadas no mercado de trabalho é o medo constante de serem rejeitados pelos colegas de profissão, assim como pela sociedade em geral, situação que faz com que estes indivíduos evitem conviver em grupos. Desse modo, as campanhas educativas e de conscientização, conduzidas pelos profissionais da área de saúde e das associações representativas destas pessoas, ainda são insuficientes ou pouco abrangentes.

\section{Fatores que facilitam a reinserção da pessoa com estoma intestinal no ambiente de trabalho}

Essa categoria é o resultado da análise das respostas dos entrevistados quando questionados sobre os fatores que facilitariam a reinserção da pessoa estomizada no mundo do trabalho. Dentre as facilidades mais citadas, está a possibilidade de realizar o sistema de irrigação da colostomia.

O sistema de irrigação é um método que controla a exoneração das fezes por meio da introdução de água potável em temperatura ambiente, uma vez por dia. A água para irrigação deve estar em temperatura próxima ao organismo, a fim de não provocar cólicas, e o volume de acordo com o peso e as condições do estomizado ${ }^{15}$.

Os participantes alegam que esta alternativa, que permite o controle das eliminações intestinais, facilita a sua rotina diária. Desta forma, conseguem programar os horários e o tempo de permanência nos lugares, evitando possíveis constrangimentos, além de se sentirem menos receosos de conviver com a população.

\section{[...] A irrigação facilita muito para quem trabalha fora.-E6}

[...] agora que estou fazendo o sistema de irrigação, facilita a minha vida em tudo, vou para qualquer lugar, usando um oclusor, agora eu consigo ficar no meio das pessoas. - E2

A possibilidade de realizar o sistema de irrigação é fundamental para o indivíduo no momento em que vai optar por voltar, ou não, ao trabalho. Por outro lado, não são todos os indivíduos colostomizados que podem fazer o processo da irrigação. Esse método se limita às pessoas que possuem estomas definitivos, colostomia em alça terminal ou reto, 
sem doenças inflamatórias intestinais e complicações e com capacidade de exercer o autocuidado $o^{7,8,13,19}$.

Outra facilidade referida pelos participantes é a possibilidade de ter um negócio próprio, pois poderiam escolher uma ocupação que envolve trabalho leve e sem exposição ao calor; fazer a higienização da colostomia a hora que precisassem; teriam flexibilidade de horário e não ficariam preocupados em serem discriminados pelas pessoas no seu local de trabalho caso venha acontecer alguma situação constrangedora em relação ao estoma.

[...] Eu acho que a pessoa estomizada não deveria trabalhar formalmente, pois esta situação é muito difícil, deveria ter um negócio próprio, eu, por exemplo, alugo imóveis. - E4

Ter um local próprio para trabalhar é melhor, posso sair para soltar os gases, posso fazer o meu horário de trabalho. - E7

[...] Flexibilidade de horário de trabalho facilitaria muito a nossa vida, pois sempre temos que ir a consultas, fazer algum exame. - E9

Segundo os participantes, ter chefes e colegas cientes do seu problema de saúde, assim como ter apoio deles, também é visto como um facilitador, além de estimular o retorno ao trabalho. Essa realidade é fundamental no dia a dia do trabalho, pois esses trabalhadores conseguiriam conciliar os cuidados com a sua saúde com as suas atividades profissionais.

No entanto, para que a equipe de trabalho entenda o que é ser um trabalhador estomizado, sugere-se que sejam fornecidas palestras educativas sobre esta problemática de saúde, inclusive trazendo um trabalhador com estomia para compartilhar como é conviver com uma colostomia. Compreende-se que esta estratégia é importante para a inclusão social do estomizado em seu local de trabalho, pois o desconhecimento da população em geral a respeito da pessoa estomizada faz com que esta seja discriminada em relação a sua capacidade produtiva.

[...] Fazer reunião com as pessoas que trabalham para falar que existe um estomizado. Fazer palestras sobre estomizados e as doenças que causam isso. Aí vai o médico da empresa, a enfermeira para explicar. Ninguém sabe o que é isso e você pode levar a empresa toda para lá. Funcionários que têm uma estomia podem dar depoimentos, aí de repente a gente não fica tão constrangida diante das intercorrências que podem acontecer no dia a dia, porque as pessoas já estão cientes do problema. - E6

Ademais, entende-se que as organizações para recolocação das pessoas estomizadas ou com outra deficiência física devem trabalhar com a sensibilização e a conscientização dos demais trabalhadores, estabelecendo uma relação de compreensão e receptividade. Daí a importância das ações educativas do enfermeiro do trabalho nessas organizações.

Portanto, os estomizados referem como fatores facilitadores para o retorno ao mercado de trabalho a possibilidade de realizar irrigação, de ter um negócio próprio, a flexibilidade de horário no trabalho e o apoio dos empregadores e colegas de trabalho.

\section{O enfermeiro no processo de retorno da pessoa com estoma intestinal ao ambiente de trabalho}

Essa categoria está relacionada à análise das respostas dos estomizados quando questionados sobre a importância do profissional de enfermagem no processo de retorno ao trabalho. Os resultados demonstraram que a importância do enfermeiro está relacionada ao papel que este profissional tem no processo de informar e orientar não somente em relação ao autocuidado, mas também nas atividades diárias de acordo com a capacidade funcional de cada estomizado, inclusive o retorno às atividades laborais.

[...] A coisa principal do enfermeiro é passar a ideia que o mundo para o estomizado não acabou, conversar, dizer que o fato de ser estomizado e trabalhar não vai prejudicar a saúde, não vai ficar mais doente, que a vida segue mesmo com esse problema.-E5

Todavia, nenhum entrevistado reporta ter recebido orientações pelo enfermeiro ou qualquer outro profissional de saúde sobre a possibilidade de trabalhar no mercado de trabalho formal ou informal. Enfatiza-se que os profissionais envolvidos com o processo de reabilitação das pessoas com estoma devem ter conhecimento sobre as atividades laborais indicadas a esta clientela e, assim, orientá-la a respeito dos seus direitos de inclusão trabalhista, incentivando-a a se reinserir no mundo do trabalho ${ }^{13-15}$.

Vale lembrar que o retorno ao trabalho faz parte do processo de reabilitação, assim como a inclusão social do indivíduo, além de que nesta etapa do processo de reabilitação 
espera-se que a pessoa com estoma seja capaz de realizar o autocuidado.

As orientações fornecidas pelos enfermeiros em relação ao retorno ao trabalho devem se centrar nas características pessoais desses indivíduos. Também devem esclarecer aos estomizados que deverão exercer atividades laborais que não prejudiquem a sua saúde. Essas pessoas deverão evitar ocupações nas quais tenham que fazer força física excessiva; que as exponham ao calor constante e a produtos químicos na região do estoma; que tenham que utilizar uniformes apertados; que não flexibilizem seu horário para que possam ir às consultas da equipe multiprofissional; que não permitam a sua ida ao banheiro quando necessário ou que não forneçam condições dignas para realização de sua higiene $e^{7,14,15}$.

O enfermeiro deve ainda informar à pessoa com estoma sobre a sua condição legal de ser incluído como pessoa com deficiência física, encaminhando-o ao serviço social, para que possa receber informações sobre os serviços disponíveis em relação a sua qualificação profissional, sobre o sistema de cotas, além das vagas destinadas nos concursos públicos. Deve ser realizado um levantamento dos dados a respeito da formação escolar e experiência dos estomizados, das atividades laborais exercidas antes do desenvolvimento do estoma e da sua vontade de reinserir-se no ambiente de trabalho $7,8,13,14$.

Além do papel do enfermeiro como educador e facilitador do processo de reabilitação das pessoas com estoma, os sujeitos deste estudo perceberam esse profissional como um elemento fundamental na divulgação sobre a temática de estomias para a sociedade em geral.

[...] O enfermeiro deve conversar, explicar como funciona, informação básica mesmo. Estomia é pouco divulgado na área da saúde, a maioria não sabe o que é isso. - E6

[...] Eu acho que os enfermeiros poderiam falar mais para as pessoas, divulgar mais o que é estomizado. Quase ninguém sabe disso. - E4

Desse modo, o papel do enfermeiro no processo de retorno ao trabalho das pessoas com estoma está relacionado ao fornecimento de informações, orientações, esclarecimentos a respeito do autocuidado com o estoma, assim como a inclusão social e as atividades produtivas fundamentadas na capacidade funcional de cada indivíduo.
Este profissional deve estar ciente de que cada pessoa estomizada é singular e tem um comportamento diferente às diversas situações que possam ocorrer no dia a dia, portanto deve focar suas ações na reestruturação dos vínculos sociais e relacionais, da autoestima e independência. Tais aspectos poderão proporcionar qualidade de vida ao trabalhador com estoma.

Neste aspecto, ressalta-se a relevância deste estudo, uma vez que seus resultados podem auxiliar na construção do conhecimento dos enfermeiros e de outros profissionais da saúde quanto aos aspectos positivos e negativos que envolvem a reinserção no ambiente de trabalho de uma pessoa com estoma intestinal definitivo.

A limitação desta pesquisa baseou-se na escassa quantidade de artigos científicos elaborados por profissionais de Enfermagem sobre a reinserção profissional do indivíduo com estoma intestinal, principalmente relacionados às orientações fornecidas pelos enfermeiros sobre este assunto. Por isso, recomenda-se que sejam desenvolvidos mais estudos a respeito desta temática, com a finalidade de contribuir para melhorias nas vidas familiar, social e laboral de tais indivíduos.

\section{CONCLUSÃO}

O desenvolvimento deste estudo atingiu os objetivos propostos que incluíam analisar os aspectos envolvidos na reinserção profissional dos estomizados e a participação do enfermeiro nesse processo. Os resultados revelaram o quanto o fato de estar exercendo alguma atividade, seja ela no mercado de trabalho formal ou informal, repercute na melhoria da qualidade de vida da pessoa com estoma. Para estes indivíduos, o trabalho tem um significado, pois ele é visto como uma estratégia de enfrentamento para a sua nova condição de vida e uma forma de evitar o afastamento do convívio social.

Quanto aos fatores que dificultam o retorno ao trabalho destes sujeitos, o uso da bolsa coletora e a falta de um banheiro adaptado às necessidades dos estomizados foram os fatores mais mencionados. Por outro lado, como fatores facilitadores, destacou-se a possibilidade de os estomizados fazerem uso da irrigação, proporcionando-lhes mais autoconfiança e autonomia no ambiente de trabalho.

Em relação ao papel do enfermeiro no processo de retorno ao trabalho das pessoas com estoma, os resultados evidenciaram que há uma lacuna a respeito da atuação 
deste profissional. Nenhum entrevistado referiu ter recebido informações e/ou orientações sobre a possibilidade de retornar ao mundo do trabalho, seja formal ou informal. Logo, sugere-se a necessidade da realização de novas pesquisas que avaliem as informações e orientações dadas pelos enfermeiros às pessoas com estoma sobre as possibilidades de sua reinserção no ambiente de trabalho. Ademais, os dados encontrados mostraram que ainda é preciso realizar abordagens e ações educativas mais abrangentes junto à sociedade em geral sobre o que é uma pessoa com estoma intestinal, a fim de minimizar os estigmas estabelecidos a estes indivíduos.

Portanto, os resultados desta investigação poderão contribuir na estruturação de novos modelos de atenção às pessoas com estoma intestinal definitivo, nos moldes da integralidade do processo de cuidar em saúde.

\section{REFERÊNCIAS}

1. Pereira CS, Prette AD, Prette AA. Qual o significado do trabalho para as pessoas com e sem deficiência física? Rev Psico USF. 2008;13(1):105-14.

2. Silva NG, Gama FA, Dutra RA. Percepção de pacientes com estomia sobre mitos e medos relacionados a esta condição. Rev Estima. 2008;6(1):22-6.

3. Perugini VC, Linhares M, Silva RD, Pereira VC, Rocha MS, Collares JV. Processo de viver com estomia: facilidades e limites. Rev Estima. 2006;4(1):1-20.

4. Santos VL, Sawaia BB. A bolsa na mediação estar ostomizado - estar profissional: análise de uma estratégia pedagógica [Internet]. Rev Latino-am Enferm. 2000 [citado 18 mar. 2015];8(3):40-50. Disponível em: http://www.scielo. $\mathrm{br} / \mathrm{pdf} / \mathrm{rlae} / \mathrm{v} 8 \mathrm{n} 3 / 12398 . \mathrm{pdf}$

5. Silva AL. O significado da mudança no modo de vida da pessoa com estomia intestinal definitiva [Internet]. Rev Latino-am Enferm. 2006 [citado 18 mar 2015];14(4):48390. Disponivel em: http://www.scielo.br/pdf/rlae/v14n4/ v14n4a03.pdf

6. Souza MP, Santos VR, Vilela BS, Paula MA. Estoma e vida laborativa. Rev Estima. 2007;5(1):13-20.

7. Mauricio VC. A pessoa estomizada e o processo de inclusão no trabalho: contribuição para a enfermagem [dissertação]. Rio de Janeiro: Faculdade de Enfermagem, Universidade do Estado do Rio de Janeiro; 2011.

8. Mauricio VC, Souza NV, Lisboa MT. Determinantes biopsicossociais do processo de inclusão laboral da pessoa estomizada [Internet]. Rev Bras Enferm. 2014 [citado 18 mar. 2015];67(3):415-21. Disponível em: http://dx.doi. org/10.5935/0034-7167.20140055

9. Brasil. Decreto-lei $n^{\circ}$ 5.296, de 2 de dezembro de 2004 Regulamenta as leis números 10.048, de 08 de novembro de 2000, que dá prioridade de atendimento às pessoas que especifica, e 10.098, de 19 de dezembro de 2000, que estabelece normas gerais e critérios básicos para a promoção da acessibilidade das pessoas portadoras de deficiência ou com mobilidade reduzida. Diário Oficial da República Federativa do Brasil. Brasília; 2004, seção 1, p. 5.

10. Brasil. Decreto n. 6.214, de 26 de setembro de 2007. Regulamenta o benefício de prestação continuada da assistência social devido à pessoa com deficiência e ao idoso de que trata a lei n. 8.742, de 7 de dezembro de 1993, e a Lei n. 10.741 , de $1^{\circ}$ de outubro de 2003, acresce parágrafo ao art. 162 do Decreto n. 3.048, de 6 de maio de 1999, e dá outras providências [Internet]. [citado 25 ago. 2013]. Disponível em: http://www.planalto.gov.br/CCIVIL_03/_ Ato2007-2010/2007/Decreto/D6214.htm

11. Brasil. Ministério da Saúde. Portaria no 1.823, de 23 de agosto de 2012: institui a Política Nacional de Saúde do Trabalhador e da Trabalhadora [Internet]. [citado 25 ago. 2013]. Disponível em: http://bvsms.saude.gov.br/bvs/ saudelegis/gm/2012/prt1823_23_08_2012.html

12. Schwalm MT, Ceretta LB, Farias BM, Bonfanti MP, Zimmermann KC, Perfoll R, et al. Perfil das pessoas estomizadas atendidas na clínica Escola de Enfermagem da Universidade do extremo sul Catarinense UNESC. Rev Iniciação Cient [Internet]. 2013 [citado 18 mar. 2015];11(1):97-105. Disponível em: http:// periodicos.unesc.net/index.php/iniciacaocientifica/article/ viewFile/1626/1538

13. Franco VQ, Maurício VC, Souza NV, Maurício CE, David HM. Inclusão laboral da pessoa estomizada sob ótica do capitalismo neoliberal. Rev Enferm Profissional [Internet]. 2014 [citado 18 mar. 2015];1(2):291-293. Disponível em: http://www.seer.unirio.br/index.php/index/search/authors/ view?firstName $=$ Vanessa\&middleName $=$ Queli\&lastName $=F$ ranco\&affiliation $=$ \& country $=\mathrm{BR}$

14 Maurício VC, Souza NV, Lisboa MT. O sentido do trabalho para o ser estomizado. Texto Contexto Enferm. 2014;23(3):656-64.

15. Maurício VC, Souza NV, Lisboa MT. O enfermeiro e sua participação no processo de reabilitação da pessoa com estoma. Esc Anna Nery Rev Enferm. 2013;17(3):416-22.

16. Cruz EJ, Souza NV, Mauricio VC. Reinserção da pessoa com estomia intestinal no mundo do trabalho: uma revisão bibliográfica. Rev Estima. 2011;9(2):31-8.

17. Minayo MC. O desafio do conhecimento. 6. ed. São Paulo, Rio de Janeiro: Hucitec, Abrasco; 1999.

18. Brasil. Ministério da Saúde. Conselho Nacional de Saúde. Diretrizes e normas regulamentadoras de pesquisa envolvendo seres humanos. Resolução n. 466, de 12 de dezembro de 2012. Brasília; 2012.

19. Coelho AR, Santos FS, Poggetto MT. Stomas changing lives: facing the illness to survive. Rev Min Enferm [Internet]. 2013 [citado 18 mar. 2015];17(2):268-77. Disponível em: http:// www.dx.doi.org/10.5935/1415-2762.20130021 